\title{
Evaluating the Readability of Radio Frequency Identification for Construction Materials
}

\author{
Younghan Jung ${ }^{1}$ and Micheal Myung Jeong ${ }^{2}$ \\ ${ }^{1}$ Assistant Professor, Engineering Technology, Old Dominion University, 102 Kaufman Hall, Norfolk, VA 23323 USA, \\ yjung@odu.edu (corresponding author). \\ ${ }^{2}$ Assistant Professor, Civil Engineering and Construction Management, Georgia Southern University, P.O. Box 8077, \\ Statesboro, GA 34060, mjeong@georgiasouthern.edu
}

Project Management

Received September 26, 2016; received revision November 2, 2016; accepted November 11, 2016

Available online November 25, 2016

\begin{abstract}
Radio Frequency Identification (RFID), which was originally introduced to improve material handling and speed production as part of supply chain management, has become a globally accepted technology that is now applied on many construction sites to facilitate real-time information visibility and traceability. This paper describes a senior undergraduate project for a Construction Management (CM) program that was specifically designed to give the students a greater insight into technical research in the CM area. The students were asked to determine whether it would be possible to utilize an RFID system capable of tracking tagged equipment, personnel and materials across an entire construction site. This project required them to set up an experimental program, execute a series of experiments, analyze the results and summarize them in a report. The readability test was performed using an active Ultra-High frequency (UHF, 433.92 $\mathrm{MHz}$ ) RFID system with various construction materials, including metal, concrete, wood, plastic, and aluminum. The readability distance distances are measured for each of the six scenarios. The distance at which a tag was readable with no obstructions was found to be an average of $133.9 \mathrm{~m}$ based on three measurements, with a standard deviation of $3.9 \mathrm{~m}$. This result confirms the manufacturer's claimed distance of $137.2 \mathrm{~m}$. The RFID tag embedded under $50.8 \mathrm{~mm}$ of concrete was readable for an average distance of only $12.2 \mathrm{~m}$, the shortest readable distance of any of the scenarios tested. At the end of the semester, faculty advisors held an open discussion session to gather feedback and elicit the students' reflections on their research experiences, revealing that the students' overall impressions of their undergraduate research had positively affected their postgraduate education plans.
\end{abstract}

Keywords: Undergraduate research, senior project, RFID, postgraduate education, construction management.

\section{Introduction}

A capstone senior project is assigned to senior-level construction management (CM) students as a core course in the curricula of CM programs in most U.S. colleges. The main purposes of these projects are to provide senior students with an opportunity to engage in a real world CM experience in a professional setting, apply the knowledge they have learned from coursework during their college years, and expand their perspectives in the CM area. To accomplish these objectives, a typical senior CM project tends to consist of primarily management-related tasks such as project estimation, scheduling and construction document preparation, following the recommendations included in the American Council for Construction Education (ACCE) accreditation guidelines. Unlike other engineering programs, CM programs rarely treat the senior project as an opportunity to focus on purely technical topics, but given the importance of facilitated problem solving in today's workplaces it is hugely important for CM programs to challenge their undergraduate students by requiring them to engage in technical research. A well- designed research project will enable students to learn how to articulate a research question, formulate a hypothesis, develop a research approach, and work with other students and faculty collaboratively, thereby also improving their learning, communication and inter-personal skills.

This paper reports how a senior project for a CM program can be used to provide such undergraduate research experiences by implementing a technical research project that was specifically designed to help a group of senior students broaden their awareness of the importance and utility of technical research. The process and results of the project are described, along with a brief discussion of the feedback obtained from the students who participated, their reflections on their experience, and the new perspectives they gained on the role of CM research.

The specific objective of the project assigned to the students was to evaluate the readability of tags on different types of building materials using a Radio Frequency Identification (RFID) reader. RFID technology has been successfully used for supply chain management, 
particularly for inventory control, for some years (Kathaswala and Tueck, 2008). Materials management that utilizes RFID for automated tracking and locating materials also promises to greatly improve productivity on construction sites by helping contractors to continuously monitor the precise locations of various materials as they are moved around individual construction sites (Razavi and Hass, 2011). However, although the application of RFID for tracking and locating activities should considerably improve material handling and productivity, on real-world construction sites the tag readability may be limited by an imperfect data acquisition process due to factors such as the type of antenna used, the height and displacement of the individual tags, and the antenna-tag distances involved (Kim et al., 2008). This research project encourages students to take the first step towards improving their understanding of how RFID readability varies with different material types, appreciate the implications of the various RFID limitations, and learn how to make the best use of the existing equipment and technology in the construction industry.

\section{Radio Frequency Identification Device}

The RFID technique is increasingly being used in automated processes of object identification (Finkenzeller, 2010). RFID has many applications to mainly help speed the handling of manufactured goods and materials form a distance (Want, 2006). An RFID reader utilizes electromagnetic fields in the form of radio waves to capture information contained in a passive or active tag (Arnold et al., 2010). Nearly all RFID systems operate on one of four frequency bands, namely, low frequency (LF, $125-134 \mathrm{kHz}$ ), high frequency (HF, $13.553-13.567 \mathrm{MHz}$ ), ultra high frequency (UHF, 400-1000MHz) and microwave (2.45GHz) (Singh et al., 2007).

The handheld reader (RX 202 serial reader), shown in Fig. 1, consists of an antenna and a microchip that is used to read the signal from a tag that stores useful data for an object using appropriate software and is usually embedded in the object (Wang, 2008). Two types of active tags are used in the experiment as shown in Fig. 1. A personal tag
(TGP-A Active Duo) is intended for use with all personnel security and access applications, and a micro tag (TGM-A) is a smallest active tag from Wavertrend. A number of applications using such RFID systems are available, with the most common areas being manufacturing, transportation and logistics, and security management (Singh et al., 2007), although they are also used for toll collection and payment, animal and human identification, and airport baggage tracking. A major advantage of using RFID is that it generally functions well even with obstacles blocking the line of sight between tag and reader (Arnold et al., 2010). RFID has been found to be particularly useful in the construction industry. Since building construction inevitably involves large amounts of diverse construction materials, this technology offers a way to track and locate both materials and equipment on construction sites. RFID systems have also been used to monitor the amount of time construction laborers spend on site and track their movements around the site.

To accomplish the study objective, the students were provided with an RFID development kit consisting of an antenna, a reader, a tag, and the appropriate software. The reader was connected via a USB port to a microprocessor controller with onboard firmware that communicated directly with the radio frequency receiver module. The total cost of this RFID development kit was $\$ 800$, including a free trial of the home automation software.

In general, construction materials management uses RFID tags for the following applications:

- To facilitate inventory control by scanning materials as they are delivered to the site

- $\quad$ To tag metallic materials to help minimize loss and support the assembly sequence during installation

- To tag non-metallic material to provide information for material management

- To control site access of personnel for security and/or safety

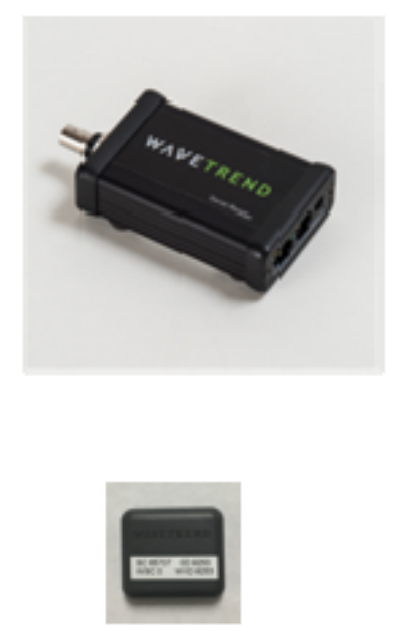

Fig. 1. Wavetrend Technologies' RFID development kit (clockwise from upper left: antenna, reader, micro tag, and personal tag) (WAVETREND) 


\section{Preliminary Study}

At the beginning of the semester, the faculty advisors developed the following research question for the student group to brainstorm and establish a valid experimental plan for investigation: "Would it be possible to utilize a tower crane as a platform for mounting an RFID system capable of tracking tagged equipment, personnel and materials across an entire construction site?” This question was based on the observation that a tower crane usually covers a large portion of a construction site and could thus provide a central location from which to oversee the RFID data collection on the jobsite.

This research topic was developed to guide the student group's exploration of the feasibility of implementing RFID technology for the management of construction materials. The group performed preliminary background research to investigate this possibility by examining the effect of site layout on different material types for a typical construction site. The following sections summarize the background research conducted by the students as they considered how RFID applications could be affected by factors connected with personnel, equipment, materials, and the site layout.

\subsection{Personnel and RFID}

Radio wave technology has advanced considerably in recent decades and RFID applications using radio waves have now been extended to both animals and humans with the approval of the Food and Drug Administration in the U.S. Given the growing popularity of this technology, there has been renewed pressure to extend this technology to the construction industry to manage construction workers more effectively. RFID is now beginning to be applied to personnel management in the construction area and its ability to track and identify individual construction workers is attracting attention from construction managers and other stakeholders.

For construction managers, it is important to understand that there are pros and cons related to using RFID technology for labor management in building construction. One positive impact for personnel management is that the technology enables managers to reduce the effort needed to validate the workers' labor time. Since the RFID reader conveniently scans and records the laborers' site entry and exit times, payroll accountability becomes more accurate and reliable in calculating the workers' compensation, thus minimizing potential disputes between workers and managers concerning the accuracy of work-hour records and reducing fraud.

Another advantage of applying RFID for labor management is ability to track and locate individual workers as they move around the site in the course of their duties. On a construction site, it is common for specific work groups, or crews, to work together to complete a particular task. For example, a group of concrete workers will work together to complete a concrete slab installation and a group of carpenters will co-operate to fabricate a set of masonry forms. RFID could be used to provide managers with information on the whereabouts of each such group over the course of the work day, enabling them to schedule operations to make the overall labor allocation more effective and maximize productivity.

Despite these advantages, there are a number of concerns associated with the use of RFID to track humans.
Since RFID tracks the workers wherever they are on site throughout the workday, privacy is likely to become an issue, with suspicions regarding potential abuses of the technology arising among those being tracked. Even when managers are explicitly prohibited from using RFID as a means of tracking the workers outside working hours, controversies related to RFID manipulation could be an issue for personnel management.

\subsection{Materials and RFID}

Material-handling using RFID technology on construction job sites is probably the most common RFID application in the construction area. Construction materials are distributed in various locations across job sites and the efficient management of materials is considered one of the major responsibilities of construction managers. Given that properly managing common construction materials such as cement, aggregates, steel bars, precast concrete blocks, pipes and wood is a key factor in the success or otherwise of a project, construction managers must always be aware of the whereabouts of all these materials, constantly updating the quantity and quality of each material group for effective operational inventory management.

RFID tags can be attached either to individual material items or a group of items, allowing the location and quantity of each material item or group to be identified by the RFID's tracking and locating function. However, there are practical challenges in using the technology to track construction materials. First, the RFID tags cannot be attached to certain types of construction materials, including stockpiled sands and gravels, small reinforcing steel bars, and cement that is not packaged in a bag. Second, difficulties can arise in counting the number of certain types of material because in some cases the tag is bigger than the material itself. Third, the type of material can itself cause problems; unlike concrete, wood and plastic, items made from aluminum and steel can impede the propagation of radio waves. Since such metal materials are common on construction sites, the use of RFID could be challenging for construction materials handling applications.

\subsection{Equipment and RFID}

Good management on a construction site is essential if the project is to be both efficient and profitable. RFID technology shows great promise for improving the management of construction equipment and thus needs to be included during the pre-construction planning stage. The general contractor should consider how best to apply the RFID technology to ensure the machinery is in the right place at the right time. With the help of RFID, construction managers should be able to find ways to reduce unnecessary equipment-related costs. For example, the location of each piece of equipment can be easily verified at all times by an RFID detector mounted on a site's tower crane via the tags attached to every item. Equipment movement can be tracked in real time, allowing the manager to monitor how individual machines move around the site. This knowledge of how often individual machines are used and how often they lie idle provides a solid foundation for more efficient equipment management in subsequent projects.

The historical information recorded by the RFID technology is an important asset for the company as it 
allows managers to accurately estimate the equipment production rate and thus calculate the owning and operating costs of each piece of equipment for a given work activity and work condition. By tracking and locating them at all times, the allocation of construction machinery becomes more organized and the overall uncertainties related to equipment management can be minimized based on this historical information.

\subsection{Site Layout}

The location of a construction job site affects the efficiency with which the RFID technology can operate. If the site is located in a rural area with no other significant radio waves close by, then the technology can perform well. However, if the site happens to be in a congested urban area where many radio signals from various devices in the surrounding area are present, the effective use of RFID is significantly limited. Whether the site is in an open area or one that incorporates blockages due to terrain or existing buildings or infrastructure elements can also be an important factor determining the RFID efficiency. Although little interference is experienced in open areas, blockages can seriously hinder the utility of RFID on a construction site.

\section{Experiment}

After conducting their preliminary research, the student group began a series of experiments designed to explore the ability of RFID to properly read tags placed in several locations typically associated with construction materials. To understand materials management in construction, students were asked to identify the materials most commonly found in construction sites and use these to conduct the tests.

\subsection{Materials}

A standard set of construction materials have been collectively designated for use in creating planned structures. In 1975, the Construction Specifications Institute (CIS) developed a standard format that organizes the major construction material types into 16 construction divisions, with each division representing a specific construction area. For example, Division 3 is for concrete work and Division 4 for masonry work. In 2004, this list was extensively revised, expanding the division list to 49. The "MasterFormat" is currently used for most U.S. commercial building design and construction projects (Construction Specifications Institute). Table 1 presents the division numbers and material types for each division following the original CIS format.

For this senior project, the students chose several material types for the RFID evaluation purpose using their own judgment. As noted earlier, materials management is a common application for RFID technology, so selecting materials of interest was an important step for the group in terms of understanding and familiarizing themselves with the technology and the associated issues related to materials management.

Table 1. CSI MasterFormat divisions and material types (construction specifications institute)

\begin{tabular}{cl}
\hline Division & \\
\hline 1 & None \\
2 & Wood, dirt, asphalt \\
3 & Steel, wood, plastic, concrete, dirt \\
4 & Steel, aluminum, plastic, bricks, slate, marble \\
5 & Steel, aluminum \\
6 & Wood, plastic, asphalt \\
7 & Aluminum, wood, plastic, concrete, bricks, ceramics, asphalt \\
8 & Steel, aluminum, wood, glass \\
9 & Aluminum, wood, plastic, concrete, bricks, slate, marble, plaster, ceramic, glass \\
10 & None \\
11 & Steel, aluminum, plastic, dirt, glass \\
12 & Steel, aluminum, plastic, concrete, bricks, glass \\
13 & Steel, aluminum, wood, plastic, concrete, bricks, marble, plaster, ceramic, glass \\
14 & Steel, aluminum, wood, plastic, concrete, dirt, bricks, slate, marble, plaster, ceramic, glass, \\
15 & asphalt \\
16 & Steel, aluminum, plastic \\
\hline
\end{tabular}




\subsection{Device and Experimental Plan}

The readability test was performed using an active 433.92MHz RFID system manufactured by Wavetrend Ltd. (Model: RX 202 hand held serial reader). According to the specifications provided by the manufacturer, the typical reading range between the tag and the reader can be as high as 137.2 meter for battery operation, with an expected battery life of 3-5 years. For the experimental component, the RFID material test was conducted three times for each of the six different scenarios shown below. The test site was the university's athletic field covered with grasses, some distance from major campus buildings. The test was conducted with two personal tags and four micro tags as followings:

- $\quad$ Unobstructed tag (personal tag)

- $\quad$ Tag embedded 50.8 millimeters $(\mathrm{mm})$ deep in a cylindrical specimen of size $101.6 \times 203.2-\mathrm{mm}$ after 28-day curing time in the air dry condition (micro tag)

- $\quad$ Tag sandwiched between two $50.8 \mathrm{~mm}$ blocks of wood (micro tag)

- $\quad$ Tag inside a plastic food container (micro tag)

- $\quad$ Tag wrapped in a single layer of $0.2-\mathrm{mm}$ aluminum foil (micro tag)

- $\quad$ Tag in a person's pocket (personal tag)

To examine how the range of RFID readability varied for different construction materials, the materials were classified into four main types for this study: metal, concrete, plastic, and wood, based on the categories used in the CSI MasterFormat division lists (Construction Specifications Institute).

The unobstructed RFID tag, which was not attached to any material object, was included to confirm the basic readability distance of 137.2 meters claimed by the manufacturer. The RFID reader was located in a fixed position and connected to the laptop through a USB cable. For each different scenario, the tag was moved in $15.2 \mathrm{~m}$ increments away from the reader, with the connectivity of the reader and the tag checked each time to determine whether the tag remained within the readable range. Once a material was deemed to be out of range, the material was then returned to the previous readable location and then moved out by successive $0.3 \mathrm{~m}$ increments to locate the outer limit more accurately. In the case of the embedded concrete, the material was moved in $3.0 \mathrm{~m}$ increments throughout due to the unwieldy nature of the sample. The experiment was repeated three times for each scenario to obtain the average and standard deviation of the readability distance.

\section{Results and Discussion}

\subsection{Readability Results}

In general, there are three types of Ultra High Frequency (UHF) RFID interference: tag interference, multiple reader-to-tag interference and reader-to-reader interference (Kim et al., 2008). The type of antenna, height of the tag, displacement of the tag, and antenna tag distance are also important factors that can affect the RFID readability. The distance measurement for RFID readability used in this test considered displacement of the tag only on a level grade, but UHF RFID interference might also influence the distance.

The readability distance distances measured for each of the six scenarios are shown in Table 2. The distance at which a tag was readable with no obstructions was found to be an average of $133.9 \mathrm{~m}$ based on three measurements, with a standard deviation of $3.9 \mathrm{~m}$. This result confirms the manufacturer's claimed distance of $137.2 \mathrm{~m}$. The RFID tag embedded under $50.8 \mathrm{~mm}$ of concrete was readable for an average distance of only $12.2 \mathrm{~m}$, the shortest readable distance of any of the scenarios tested. This result indicates that the communication between tag and RFID is hindered considerably by the hardened concrete material and this poor performance may be compounded by the need to wrap the tag with a thin layer of plastic when it is embedded in concrete. The measurements for the concrete material scenario were also the least consistent; the coefficient of Variation (CV) of $10.7 \%$ suggests that the compatibility of concrete material with RFID is quite poor.

The RFID readability for the plywood and aluminum materials and in a worker's pocket were very similar, with average distances of $64.5,52.4$, and $59.4 \mathrm{~m}$, respectively. The CV values were also lower than that of the concrete material, indicating a more consistent performance. The plastic material test showed the most consistent results, with a CV of only $0.7 \%$. The readability distance for this scenario was $86.1 \mathrm{~m}$, the longest of all the scenarios except for the unobstructed test.

Table 2. RFID readability test results

\begin{tabular}{|c|c|c|c|c|c|c|}
\hline \multirow[t]{2}{*}{ Type of material } & \multicolumn{3}{|c|}{$\begin{array}{c}\text { Distance in meters (m) for Each } \\
\text { Test }\end{array}$} & \multirow[t]{2}{*}{ Average (m) } & \multirow{2}{*}{$\begin{array}{c}\text { Standard } \\
\text { deviation (m) }\end{array}$} & \multirow{2}{*}{$\begin{array}{l}\text { Coefficient o } \\
\text { variation (\%) }\end{array}$} \\
\hline & Test 1 & Test 2 & Test 3 & & & \\
\hline Unobstructed (no material) & 137.2 & 129.5 & 135.0 & 133.9 & 3.9 & $2.9 \%$ \\
\hline Embedded: 50.8 mm concrete & 10.4 & 11.3 & 12.8 & 11.5 & 1.2 & $10.7 \%$ \\
\hline Embedded: 50.8 mm plywood & 64.3 & 63.7 & 65.5 & 64.5 & 0.9 & $1.4 \%$ \\
\hline Plastic container & 85.3 & 86.6 & 86.3 & 86.1 & 0.6 & $0.7 \%$ \\
\hline $0.2 \mathrm{~mm}$ aluminum & 54.1 & 54.3 & 48.8 & 52.4 & 3.1 & $6.0 \%$ \\
\hline Pocket (personnel) & 61.0 & 57.9 & 60.4 & 59.7 & 1.6 & $2.7 \%$ \\
\hline
\end{tabular}




\subsection{Student Feedback and Reflection}

At the end of the semester, the faculty advisors held an open discussion session with the students who participated in this project. The purpose was twofold: firstly, to discuss the students' thoughts and reflections on the project and secondly, to explore their perceptions and notions regarding their undergraduate research experience and how these had affected their postgraduate education plans. The faculty members asked the group the following questions and the students were encouraged to answer in an open and non-judgmental environment:

- How do you think the research experience affected your plans for higher education?

- What was the biggest challenge while doing the research?

- What was the most valuable lesson you learned while doing the research?

- What was the overall level of difficulty in doing the research?

Regarding the project's impact on their decisions regarding higher education, the team agreed that the research positively affected their perceptions of higher education, although they also noted that they would not pursue a Master's degree immediately after graduation. The biggest challenge in the research was their inadequate technical background in RFID, they reported. Although they dedicated their time to this project for the entire semester, it was difficult for them to understand the technical background of the RFID technology well enough to conduct the related research. They reflected that they had learned multiple valuable lessons during the research. One of the students mentioned that the preliminary research was the most important step. He added that without sufficient background knowledge of a research topic, conducting research would be extremely difficult and the results might not be valid. Another pointed out that another lesson was that teamwork played an important role in doing a research project. One student also mentioned that a poorly designed experimental plan could cause a huge waste of time. Concerning the overall difficulty, the students agreed that the level was mediocre.

\section{Conclusions}

Traditionally, an undergraduate senior project is an exercise in estimating and scheduling using construction documents from an actual building project utilizing major elements of the CM program that students have learned during their coursework. This generally includes developing a fictitious construction company organization, production of a project estimate and schedule and preparing a construction bid and construction documentation, based on a team approach. Construction related programs in universities are mainly offers a senior project or a capstone project as a part of degree completion, rather students' research participation. Over the past 20 years, the National Science Foundation (NSF), the National Academies of Science (NAS), and professional societies such as the Accreditation Board for Engineering and Technology (ABET) have all expanded their policy focus beyond their traditional support for basic and applied research in science, technology, engineering, and mathematics (STEM) to include improving the quality of undergraduate teaching and student learning in these disciplines (Fairweather, 2008). In the Architectural, Engineering and Construction (AEC) industry, this has meant adopting new technologies to improve every aspect of construction, including productivity, safety, material handling, estimating, and inspection, among others. In general, undergraduate students' participation in hands-on research is widely believed to encourage them to pursue advanced degrees and careers in STEM (Russell, et al., 2007). However, undergraduate students in construction related programs have little research experience in using and evaluating newly available technologies and their potential application for improving the construction process except for software in the form of computer applications such as scheduling and Building Information Modeling (BIM).

Engaging in technical research such as the project described here as a senior capstone project has helped both faculty members and students expand their knowledge via hands-on trials of new and innovative technological applications to the AEC industry. Although the students found the project challenging, particularly in the early stages as they began to actively participate in the research, they were eventually able to learn how a research project progresses and how each step in research is based on teamwork. They learned how to recognize the capabilities and limitations of RFID technology designed to accurately identify materials stored within containers or otherwise hidden from view. The students benefitted from the opportunity to learn how to develop and establish the basic concepts involved in integrating new technological applications into the construction process. Above all, these students have gained invaluable research experience that will strengthen their academic foundation in preparation for their future graduate studies and careers.

\section{References}

Arnold, J. R. T., Chapman, S. N., and Clive, L. M. (2010). Introduction to Materials Management (7th ed.). Upper Saddle River, NJ: Prentice Hall.

Fairweather, J. (2008). Linking Evidence and Promising Practices in Science, Technology, Engineering, and Mathematics (STEM) Undergraduate Education: A status report for the National Academies Research Council Board of Science Education.

http://www.nationalacademies.org/bose/Promising\%2 OPractices_Homepage.html

Finkenzeller, K. (2010). RFID Handbook. Wiley, http://dx.doi.org/10.1002/9780470665121

Kathawala, Y. A. and Tueck, B. (2008). The Use of RFID for Traffic Management. International Journal of Technology, Policy, and Management, 8(2), 111-125. http://dx.doi.org/10.1504/IJTPM.2008.017215

Kim, D., Yook, J., Yoon, H., and Jang, B. (2008). Interference Analysis of UHF RFID Systems. Progress In Electromagnetics Research B, 4, 115-126. http://dx.doi.org/10.2528/PIERB08010607

MasterFormat Numbers and Titles. The Construction Specifications http://www.csinet.org/numbersandtitles

Razavi, S. N. and Hass, C. T. (2011). Using Reference RFID Tags for Calibrating the Estimated Locations of Construction Materials. Automation in Construction, 20, http://dx.doi.org/10.1016/j.autcon.2010.12.009

Russell, S. H., Hancock, M. P., and McCullough, J. (2007). Benefits of Undergraduate Research Experiences. Science, 316, 548-549. 
20 Jung, Y. and Jeong, M. M.

Singh, P., McCartney, M., Singh, J., and Clarke, R. (2007). RFID Research and Testing for Packages of Apparel, Consumer Goods and Fresh Produce in the Retail Distribution Environment. Packaging Technology \& Science, 21(2), 91-102. http://dx.doi.org/10.1002/pts.782

Wang, L. C. (2008). Enhancing Construction Quality Inspection and Management Using RFID Technology. Automation in Construction, 17, 467-479. http://dx.doi.org/10.1016/j.autcon.2007.08.005

Want, R. (2006) An introduction to RFID technology, IEEE Pervasive Computing, vol. 5, no. 1, 25-33, Jan.March 2006.

WAVETREND homepage.

http://www.wavetrend.net/activ-tags.php

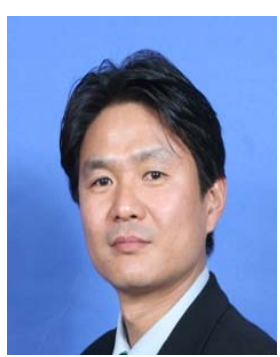

Younghan Jung, Ph.D., LEED AP $\mathrm{BD}+\mathrm{C}$ is an assistant Professor in the Department of Engineering Technology at Old Dominion University, VA. His research interests center around Occupational Safety and Health, Visualization, Organizational Intelligence, and Sustainability.

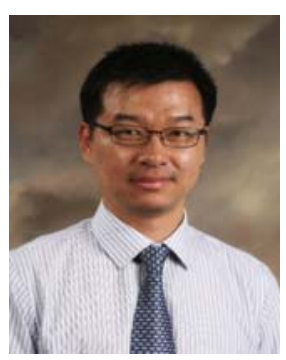

M. Myung Jeong, Ph.D, is an assistant professor in the department of Civil Engineering and Construction Management at Georgia Southern University. His research interests include roadway materials and construction, Performance-Related Specifications for pavement, and statistical modeling and analysis. 